\title{
Associations between LSAMP gene polymorphisms and major depressive disorder and panic disorder
}

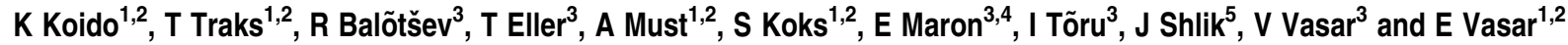

The purpose of this case-control genetic association study was to explore potential relationships between polymorphisms in the limbic system-associated membrane protein (LSAMP) gene and mood and anxiety disorders. A total of 21 single-nucleotide polymorphisms (SNPs) from the LSAMP gene were analyzed in 591 unrelated patients with the diagnoses of major depressive disorder (MDD) or panic disorder (PD) and in $\mathbf{3 8 4}$ healthy control subjects. The results showed a strong association between LSAMP SNPs and MDD, and a suggestive association between LSAMP SNPs and PD. This is the first evidence of a possible role of LSAMP gene in mood and anxiety disorders in humans.

Translational Psychiatry (2012) 2, e152; doi:10.1038/tp.2012.74; published online 14 August 2012

\section{Introduction}

Major depressive disorder (MDD) and panic disorder (PD) are prevalent and serious psychiatric disorders commonly manifesting in young adult age and affecting females more often than males. ${ }^{1,2}$ The data from twin and family studies suggest a substantial involvement of genetic factors in the familial transmission of MDD and PD, with heritability estimates for MDD in the range of $31-42 \%,{ }^{3}$ or as high as $70 \%,{ }^{4}$ and for PD near $40 \% .{ }^{5}$ It has been established that MDD and PD are highly comorbid and that shared genetic risk factors largely account for their comorbidity. ${ }^{6}$ However, the specific genes or their variants responsible for heritability or expression of these disorders remain undetermined.

The limbic system-associated membrane protein (LSAMP) is a 64- to 68-kDa glycoprotein that is found on the somata and dendrites of neurons of cortical and subcortical regions comprising the adult mammalian limbic system, which is involved in the mediation of emotional behavior, learning, memory and central autonomic regulation. ${ }^{7,8}$ LSAMP is a member of immunoglobulin superfamily, with three immunoglobulin domains and a glycosyl-phosphatidylinositol anchor. ${ }^{9}$ It has been suggested that LSAMP acts as a necessary molecular component for the formation of proper connections between the limbic system regions. ${ }^{7}$ In humans, the LSAMP gene is located in the 3q13.2-q21 chromosomal region, which consists 7 exons and shows $94 \%$ identity at the nucleotide level, and $99 \%$ sequence identity at the encoded 338-amino-acid polypeptides level with rat LSAMP cDNA. ${ }^{10}$ Human studies have shown that $L S A M P$ may have a role in the neurobiology of suicidal behavior. ${ }^{11}$ Proteomic assessment has strongly implicated LSAMP in schizophrenia and bipolar disorder, ${ }^{12}$ demonstrating its increased level in the dorsolateral prefrontal cortex. Furthermore, stronger or weaker linkages have been shown in the long arm of chromosome 3 with recurrent early-onset MDD or anxiety, ${ }^{13}$ agoraphobia, ${ }^{14}$ schizophrenia, ${ }^{15-18}$ bipolar disorder ${ }^{19,20}$ and autismspectrum disorders. ${ }^{21} \mathrm{~A}$ number of genome-wide association studies of depression have mainly given results that did not meet a genome-wide threshold for significance, but there were associations between depression and LSAMP or adjacent gene loci in top findings of all publications. ${ }^{22-29}$

In animal studies, it has been shown that the anxious rats display 1.6-fold higher expression of $L$ samp gene compared to the non-anxious rats in the periaqueductal gray. ${ }^{30}$ Similar results have been reported for the amygdala, demonstrating that the anxious rats display 2.4-fold higher expression of the Lsamp gene compared with the non-anxious rats. ${ }^{31}$ Upregulated Lsamp expression was also detected in the raphe, the hippocampus and the frontal cortex of the highly anxious rats. ${ }^{32}$ The studies in Lsamp-deficient mice demonstrated the reduced anxiety and increased sensitivity to anxiolytic action of diazepam in these animals. ${ }^{33}$ The findings above suggest the importance of LSAMP in emotional regulation and make the LSAMP gene a good candidate for genetic research on mood and anxiety disorders. The purpose of the present study was to detect associations of genetic polymorphisms in the LSAMP gene with MDD and PD.

\section{Materials and methods}

Subjects and psychiatric assessment. Unrelated patients with the diagnoses of MDD or PD $(n=591)$ were enrolled in the study along with healthy control individuals $(n=384)$. The patients were recruited from consecutive outpatients and inpatients at the Clinic of Psychiatry of the Tartu University

\footnotetext{
${ }^{1}$ Department of Physiology, University of Tartu, Tartu, Estonia; ${ }^{2}$ Centre of Excellence for Translational Medicine, University of Tartu, Tartu, Estonia; ${ }^{3}$ Department of Psychiatry, University of Tartu, Tartu, Estonia; ${ }^{4}$ Department of Neuropsychopharmacology and Molecular Imaging, Imperial College London, London, UK and ${ }^{5}$ Department of Psychiatry, University of Ottawa, Ottawa, ON, Canada Correspondence: Dr K Koido, Department of Physiology, University of Tartu, 19 Ravila Street, Tartu 50411, Estonia.

E-mail: kati.koido@ut.ee
}

Keywords: case-control association study; LSAMP; major depressive disorder; panic disorder; SNP

Received 10 April 2012; revised 2 July 2012; accepted 5 July 2012 
Hospital, and healthy subjects were recruited by newspaper advertisement in Tartu, Estonia. The diagnostic status of the patients was substantiated by a psychiatric interview and verified by the Mini International Neuropsychiatric Interview (MINI 5.0.0) based on DSM-IV criteria. ${ }^{34}$ Controls were evaluated by the MINI and family history interview, to exclude those with psychiatric morbidity and a history of major psychiatric disorders in first-degree relatives. All subjects were of white European ancestry and living in Estonia. The patients were divided into $\operatorname{MDD}(n=395)$ and $\operatorname{PD}(n=196)$ subgroups according to the primary diagnosis. MDD or PD was considered primary if it was the principal diagnosis at the time of the investigation and/or had an earlier onset in the course of illness. Patients in MDD group were either pure MDD or MDD comorbid with anxiety disorders. Patients in PD group were either pure PD, or comorbid with mood or other anxiety disorders. The control group was the same for MDD and PD, with an exception of reducing the number of male subjects in control group for PD to reflect the respective male/female ratio in the PD group. There were no significant differences in age or sex between the patients and healthy controls $\left(\chi^{2}\right.$ and $P$-value for gender of MDD and PD groups are 2.74 and $P=0.098$, and 3.35 and $P=0.067$, respectively). Demographic characteristics of the study subjects are presented in Table 1. The study protocol was approved by the Ethics Review Committee on Human Research of the University of Tartu. Each subject provided a written informed consent before participation.

SNP selection, DNA preparation and genotyping. Tag single-nucleotide polymorphisms (SNPs) were selected from the $L S A M P$ gene and flanking regions $(150 \mathrm{~kb}$ fragment from 116931222-117081732; and $242 \mathrm{~kb}$ fragment from 117428563-117670401) using the Tagger algorithm $\left(r^{2}=0.8\right.$, minor allele frequency $>0.05$ ) implemented in Haploview 3.32. ${ }^{11}$ Standard high-salt extraction method was used to isolate genomic DNA from $9 \mathrm{ml}$ venous blood samples. SNP detection was performed by SNPlex Genotyping System (Applied Biosystems, Foster City, CA, USA). This system is based on the oligonucleotide ligation/PCR assay with a universal ZipChute (Applied Biosystems) probe detection for high throughput SNP genotyping. Fluorescent-labeled ZipChute probes are hybridized to complementary ZipCode (Applied Biosystems) sequences that are part of genotypespecific amplicons. These ZipChute probes are eluted and detected by electrophoretic separation on Applied Biosystems 3730 DNA Analyzers. The system analysis software collects and manages raw data and provides automated allele calling and quality metrics. ${ }^{35}$

Table 1 Demographic characteristics of the subjects

\begin{tabular}{lcccc}
\hline Characteristic & $\begin{array}{c}\text { MDD } \\
\text { patients }\end{array}$ & $\begin{array}{c}\text { MDD } \\
\text { controls }\end{array}$ & $\begin{array}{c}P D \\
\text { patients }\end{array}$ & $\begin{array}{c}P D \\
\text { controls }\end{array}$ \\
\hline$N$ & 395 & 384 & 196 & 364 \\
Sex (male/female) & $114 / 281$ & $132 / 252$ & $46 / 150$ & $112 / 252$ \\
Age (years), & $37.0 \pm 13.8$ & $37.6 \pm 13.6$ & $38.1 \pm 12.7$ & $37.8 \pm 13.6$ \\
mean \pm s.d. & $17-73$ & $16-71$ & $18-73$ & $16-71$ \\
Range (years) & & & & \\
\hline
\end{tabular}

Abbreviations: MDD, major depressive disorder; PD, panic disorder.
Statistical analysis. Genotypes were determined by GeneMapper 3.7 (Applied Biosystems). Allelic association, linkage disequilibrium and haplotype analyses between groups of patients and controls, and Hardy-Weinberg equilibrium calculations in the control group were performed using Haploview Version 4.0 software. $^{36}$ The significance level for all statistical tests was 0.05 . The algorithm for defining haplotype blocks was an internally developed method Solid Spine of linkage disequilibrium $\left(D^{\prime}>0.75\right)$. Ten thousand permutations were used to correct $P$-values for multiple testing. Closer analysis of haplotype block $\mathrm{nr} 5$ was performed with Statistica software (Information Technology Office, University of Tartu, Tartu, Estonia).

\section{Results}

We genotyped a total of 22 SNPs from the LSAMP gene in 591 unrelated psychiatric patients and 384 healthy controls. One SNP (rs4831129) was excluded from the further analysis because of a bias from Hardy-Weinberg equilibrium in the control group ( $P$-value cut-off 0.01$)$.

Allelic association analysis. The results of allelic association analysis of 21 SNPs are presented in Table 2. Four SNPs showed significant associations in MDD group-rs16824691, rs1461131, rs4831089 and rs9874470 ( $P$-values 0.004, $<0.001,<0.001$ and $<0.001$, respectively). For the last three of these SNPs, the $P$-values remained statistically significant after 10000 permutations (odds ratios, 95\% confidence intervals and permutation $P$-values $1.43,1.17-1.76$ and 0.0228 ; 1.53, 1.24-1.89 and 0.0015; and 0.63, 0.5-0.78 and 0.0005, respectively). Two SNPs showed significant associations in PD group-rs1461131 and rs4831089 ( $P$-values 0.033 and 0.018 , respectively). These $P$-values did not remain statistically significant after correction for multiple testing.

A separate analysis of allelic association by gender revealed significant associations with the same four SNPs as whole-group analysis. The SNPs rs1461131, rs4831089 and rs9874470 ( $P$-values $0.005,0.005$ and 0.007 , respectively) differed significantly between females of the MDD group and their respective controls. No significant association was detected in the female PD group. The SNPs rs1682469, rs4831089 and rs9874470 ( $P$-values $0.01,0.004$ and $<0.001$, respectively) differed significantly between males of the MDD group and their controls. The SNPs rs1461131, rs4831089 and rs9874470 ( $P$-values $0.003,0.005$ and 0.03 , respectively) differed significantly between males of $P D$ group and their controls. These $P$-values did not remain statistically significant after correction for multiple testing, except rs9874470 in the male MDD group (odds ratio ( $95 \%$ confidence intervals) $=$ 0.49 (0.33-0.73); permutation $P=0.01$ ).

Haplotype analysis. Haplotype analysis revealed seven haplotype blocks in both patient groups (see Figure 1 for haplotype blocks in MDD group). Haplotypes of block nr 5 (rs9874470, rs4831089, rs16824691 and rs1461131) in MDD and PD groups differed statistically significantly between patient groups and healthy control groups (Tables 3 and 4). Haplotype TATA was a risk haplotype in MDD group $(P<0.001)$ and in PD group $(P=0.020)$. $P$-value remained 
Table 2 Results of allelic association analysis

\begin{tabular}{|c|c|c|c|c|c|c|c|c|c|}
\hline \# & Name & Area & $\begin{array}{l}\text { Major/minor } \\
\text { alleles }\end{array}$ & $\begin{array}{l}\text { Min allele } \\
\text { frequency of } \\
\text { MDD cases }\end{array}$ & $\begin{array}{c}\text { Min allele } \\
\text { frequency of } \\
\text { MDD controls }\end{array}$ & $\begin{array}{c}M D D \\
\mathrm{P}-\text {-value }\end{array}$ & $\begin{array}{l}\text { Min allele } \\
\text { frequency of } \\
P D \text { cases }\end{array}$ & $\begin{array}{l}\text { Min allele } \\
\text { frequency of } \\
P D \text { controls }\end{array}$ & $\begin{array}{c}P D \\
\text { P-value }\end{array}$ \\
\hline 1 & rs16824996 & $5^{\prime}$-Flanking region & $\mathrm{T} / \mathrm{C}$ & 0.14 & 0.15 & 0.380 & 0.14 & 0.15 & 0.585 \\
\hline 2 & rs6787168 & $5^{\prime}$-Flanking region & $\mathrm{T} / \mathrm{C}$ & 0.33 & 0.37 & 0.081 & 0.36 & 0.37 & 0.623 \\
\hline 3 & rs4831140 & $5^{\prime}$-Flanking region & $\mathrm{A} / \mathrm{T}$ & 0.21 & 0.25 & 0.123 & 0.24 & 0.25 & 0.552 \\
\hline 4 & rs988803 & Intron 1 & T/A & 0.24 & 0.24 & 0.887 & 0.23 & 0.25 & 0.586 \\
\hline 5 & rs7634137 & Intron 1 & $\mathrm{~T} / \mathrm{C}$ & 0.16 & 0.18 & 0.167 & 0.15 & 0.18 & 0.277 \\
\hline 6 & rs1920191 & Intron 1 & $\mathrm{G} / \mathrm{A}$ & 0.28 & 0.29 & 0.618 & 0.28 & 0.30 & 0.595 \\
\hline 7 & rs1461131 & Intron 1 & $\mathrm{G} / \mathrm{A}$ & 0.44 & 0.36 & $<0.001^{\star}$ & 0.43 & 0.37 & 0.033 \\
\hline 8 & rs16824691 & Intron 1 & $\mathrm{~T} / \mathrm{A}$ & 0.19 & 0.26 & 0.004 & 0.23 & 0.26 & 0.210 \\
\hline 9 & rs4831089 & Intron 1 & $\mathrm{G} / \mathrm{A}$ & 0.43 & 0.33 & $<0.001^{\star}$ & 0.41 & 0.34 & 0.018 \\
\hline 10 & rs9874470 & Intron 1 & $\mathrm{~T} / \mathrm{C}$ & 0.26 & 0.36 & $<0.001^{\star}$ & 0.31 & 0.36 & 0.059 \\
\hline 11 & rs2944425 & Intron 3 & $\mathrm{C} / \mathrm{T}$ & 0.41 & 0.41 & 0.794 & 0.41 & 0.41 & 0.796 \\
\hline 12 & rs9830559 & Intron 3 & $\mathrm{~T} / \mathrm{C}$ & 0.41 & 0.40 & 0.765 & 0.41 & 0.40 & 0.798 \\
\hline 13 & rs10511350 & Intron 3 & $\mathrm{G} / \mathrm{C}$ & 0.10 & 0.11 & 0.541 & 0.13 & 0.11 & 0.310 \\
\hline 14 & rs6763835 & Intron 4 & $\mathrm{C} / \mathrm{T}$ & 0.40 & 0.39 & 0.803 & 0.39 & 0.39 & 0.921 \\
\hline 15 & rs4416377 & Intron 4 & $\mathrm{~T} / \mathrm{C}$ & 0.21 & 0.21 & 0.866 & 0.21 & 0.21 & 0.974 \\
\hline 16 & rs2918213 & Intron 6 & $\mathrm{C} / \mathrm{T}$ & 0.32 & 0.33 & 0.629 & 0.33 & 0.33 & 0.981 \\
\hline 17 & rs2918215 & Intron 6 & $\mathrm{G} / \mathrm{A}$ & 0.09 & 0.11 & 0.362 & 0.10 & 0.11 & 0.570 \\
\hline 18 & rs2918217 & Intron 6 & $\mathrm{G} / \mathrm{A}$ & 0.14 & 0.13 & 0.385 & 0.14 & 0.13 & 0.727 \\
\hline 19 & rs9822311 & Intron 6 & $\mathrm{G} / \mathrm{C}$ & 0.29 & 0.27 & 0.428 & 0.29 & 0.27 & 0.559 \\
\hline 20 & rs9821809 & $3^{\prime}$-Flanking region & $\mathrm{G} / \mathrm{A}$ & 0.21 & 0.22 & 0.694 & 0.19 & 0.22 & 0.244 \\
\hline 21 & rs2918239 & $3^{\prime}$-Flanking region & $\mathrm{T} / \mathrm{G}$ & 0.16 & 0.16 & 0.861 & 0.15 & 0.15 & 0.774 \\
\hline
\end{tabular}

Abbreviations: MDD, major depressive disorder; Min allele, minor allele; PD, panic disorder.

$P$-value $\leqslant 0.05$ bolded

${ }^{\star} P$-value $\leqslant 0.05$ after 10000 permutations.

statistically significant after 10000 permutations in MDD group (odds ratio (95\% confidence intervals) $=1.55(1.26-1.91)$; permutation $P=0.0008$ ), but did not survive the correction in the PD group. Two haplotypes were protective in the MDD group-CGAG and CGTG, with respective $P=0.003$ and $P=0.020$. These $P$-values did not remain statistically significant after correction for multiple testing. ATT-risk haplotype from block $\mathrm{nr} 7$ (rs4831140, rs6787168 and rs16824996) differed statistically significantly in the MDD group $(P=0.042)$, but this $P$-value also did not survive the correction. Other haplotypes did not significantly differ between the patient and control groups (data not shown). On a closer analysis of frequencies of minor alleles of haplotype block $\mathrm{nr} 5$, the risk haplotype TATA appeared more frequently than protective haplotype CGAG in the MDD group (41 vs $17 \%$ ) as compared with their respective control group (31 vs $23 \%$; $\chi^{2}$-test $\left.P<0.001\right)$. The same trend was observed in PD grouprisk haplotype TATA was more frequent than protective haplotype CGAG (38 vs 20\%) as compared with their respective control group ( 31 vs $24 \%$; $\chi^{2}$-test $P=0.003$ ).

\section{Discussion}

Our findings indicate that the $L S A M P$ gene is possibly related to MDD and PD. We detected statistically significant allelic associations between four LSAMP SNPS and MDD. Two SNPs out of these four contributed to the increased risk (rs1461131 and rs4831089) and two were protective (rs16824691 and rs9874470). Only two risk SNPs above were related to PD. Haplotype block $\mathrm{nr} 5$ was formed from the forenamed SNPS giving three statistically significant haplotypes in the MDD group: TATA being risk haplotype and CGAG and CGTG being a protective haplotype. Risk haplotype TATA was also statistically significant in the PD group. Closer analysis of minor alleles of haploblock 5 indicated that the proportion of risk SNPs was higher in patient groups as compared with control groups. Sub-analysis by gender suggested that $L S A M P$ gene polymorphisms are evidently more related to males than to females, as no statistically significant association was detected in the female PD group. Plausibly, LSAMP gene polymorphisms contribute to shared genetic factors of MDD and PD, as associations were detected across both groups.

The LSAMP gene and protein show high similarity between the humans and rodents, suggesting strong phylogenetic conservation of the protein structure and associated functional properties. ${ }^{10}$ The LSAMP gene has two alternative first exons (1a and $1 \mathrm{~b}$ ) separated by a 1.5-Mb-long intron, which give rise to two different $\mathrm{mRNA}$ transcripts. ${ }^{37} \mathrm{~A}$ preliminary in situ RNA hybridization analysis has demonstrated substantially different expression patterns of Lsamp 1a and $1 \mathrm{~b}$ transcripts in mouse brain, with the $1 \mathrm{~b}$ predominantly expressed in sensory nuclei of the brainstem, in the thalamus and in sensory areas of the cortex (Philips et al., unpublished). It has been suggested that large $5^{\prime}$-introns contain regulatory elements involved in silencing and spatial and temporal patterns of gene expression. ${ }^{37}$ Interestingly, all associated SNPs in our study reside in the first intron (1b) and may affect regulation of gene expression. Two different Lsamp gene knockout mouse lines have been created. $^{33,38}$ Overlapping between the phenotype of these lines is remarkable; both knockout mice are vital and fertile with no gross abnormalities. $^{33}$ The first line, in which the second exon of Lsamp is deleted, exhibits hyperactivity in novel situations, altered synaptic transmission and impaired plasticity in the hippocampus, inducing deficits in spatial memory acquisition and retention. ${ }^{38,39}$ The other line, in which the $1 \mathrm{~b}$ exon of Lsamp is deleted, exhibits slower swim velocity, hyperactivity in novel situations, reduced anxiety, reduced aggressiveness and decrease of barbering behavior in male mice; however, their 


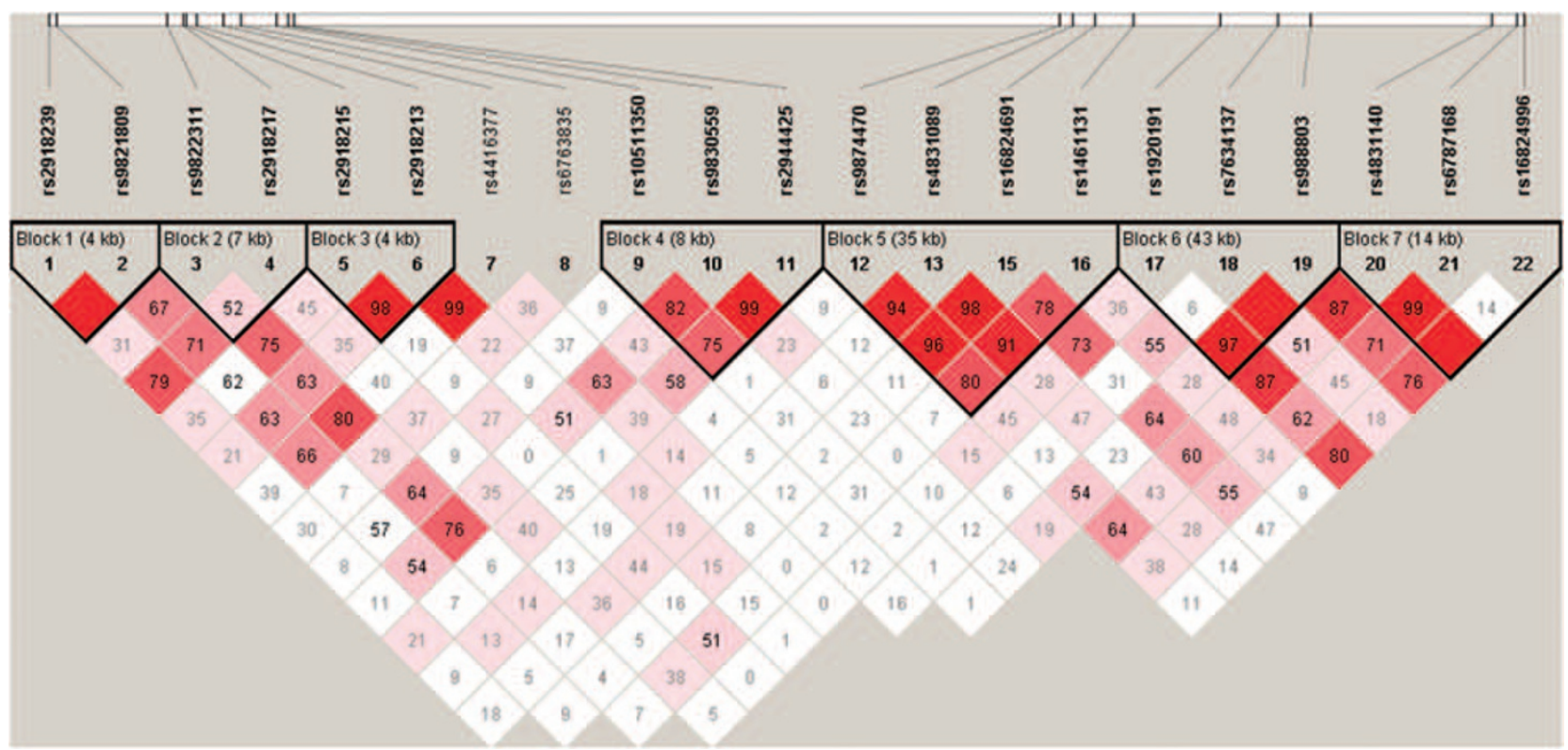

Figure 1 Haplotype blocks of the limbic system-associated membrane protein (LSAMP) gene in major depressive disorder (MDD) group.

Table 3 Haplotypes of block 5 in MDD group

\begin{tabular}{|c|c|c|c|c|c|c|c|}
\hline rs9874470 T/C & rs4831089 G/A & rs16824691 T/A & rs $1461131 \mathrm{G} / \mathrm{A}$ & $\begin{array}{l}\text { Haplotype } \\
\text { frequencies }\end{array}$ & $\begin{array}{c}\text { Case } \\
\text { frequencies }\end{array}$ & $\begin{array}{c}\text { Control } \\
\text { frequencies }\end{array}$ & P-value \\
\hline $\mathrm{T}$ & $A$ & $\mathrm{~T}$ & $A$ & 0.36 & 0.41 & 0.31 & $<0.001^{*}$ \\
\hline $\mathrm{T}$ & $\mathrm{G}$ & $\mathrm{T}$ & $\mathrm{G}$ & 0.29 & 0.29 & 0.29 & 0.932 \\
\hline$C$ & $\mathrm{G}$ & $A$ & $\mathrm{G}$ & 0.20 & 0.17 & 0.23 & 0.003 \\
\hline $\mathrm{C}$ & $\mathrm{G}$ & $\mathrm{T}$ & $\mathrm{G}$ & 0.09 & 0.07 & 0.10 & 0.020 \\
\hline $\mathrm{T}$ & $\mathrm{G}$ & $\mathrm{T}$ & A & 0.02 & 0.02 & 0.02 & 0.403 \\
\hline $\mathrm{T}$ & A & $\mathrm{T}$ & $\mathrm{G}$ & 0.02 & 0.02 & 0.02 & 0.961 \\
\hline$C$ & $\mathrm{G}$ & $A$ & A & 0.02 & 0.01 & 0.02 & 0.423 \\
\hline
\end{tabular}

Abbreviation: MDD, major depressive disorder

$P$-value $\leqslant 0.05$ bolded.

${ }^{\star} P$-value $\leqslant 0.05$ after 10000 permutations.

Table 4 Haplotypes of block 5 in PD group

\begin{tabular}{|c|c|c|c|c|c|c|c|}
\hline rs9874470 T/C & rs4831089 G/A & rs16824691 T/A & $r s 1461131 \mathrm{G} / \mathrm{A}$ & $\begin{array}{l}\text { Haplotype } \\
\text { frequencies }\end{array}$ & $\begin{array}{c}\text { Case } \\
\text { frequencies }\end{array}$ & $\begin{array}{c}\text { Control } \\
\text { frequencies }\end{array}$ & P-value \\
\hline $\mathrm{T}$ & $A$ & $\mathrm{~T}$ & $A$ & 0.34 & 0.38 & 0.31 & 0.020 \\
\hline $\mathrm{T}$ & $\mathrm{G}$ & $\mathrm{T}$ & $\mathrm{G}$ & 0.28 & 0.27 & 0.28 & 0.757 \\
\hline C & $\mathrm{G}$ & $A$ & $\mathrm{G}$ & 0.22 & 0.20 & 0.24 & 0.124 \\
\hline $\mathrm{C}$ & $\mathrm{G}$ & $\mathrm{T}$ & $\mathrm{G}$ & 0.09 & 0.08 & 0.10 & 0.330 \\
\hline $\mathrm{T}$ & $\mathrm{G}$ & $\mathrm{T}$ & A & 0.02 & 0.01 & 0.02 & 0.248 \\
\hline $\mathrm{T}$ & $A$ & $\mathrm{~T}$ & $\mathrm{G}$ & 0.02 & 0.02 & 0.02 & 0.858 \\
\hline$C$ & $\mathrm{G}$ & $A$ & A & 0.02 & 0.02 & 0.02 & 0.845 \\
\hline
\end{tabular}

Abbreviation: PD, panic disorder.

$P$-value $\leqslant 0.05$ bolded.

spatial memory and learning curve were similar to that of wild-type mice. ${ }^{33,40}$ Altogether, these results suggest that altered expression of LSAMP leads to differences in neuronal connectivity, causing only subtle disturbance in signaling but measurable changes in functional output. ${ }^{38}$ Furthermore, the lack of LSAMP protein seems to result in an inability to adapt or react to novel environments or stressful environmental manipulations. ${ }^{40}$ Thus, a properly regulated level of LSAMP expression appears to be required for normal neuronal functioning. A former study has demonstrated that intraventricular administration of anti-LSAMP to postnatal rats resulted in aberrant growth of the mossy fiber projection in the hippocampus. ${ }^{9}$ However, more recent study showed no major alterations in the brain organization and gross connectivity in the Lsamp-deficient mouse. ${ }^{38}$ To our knowledge, the direct impact of LSAMP overexpression on neuronal 
circuitry has not yet been investigated, but the animal studies indicate a relationship between heightened expression of LSAMP and anxiety. Our speculation is that risk SNPs in $1 \mathrm{~b}$ intron may cause an increased expression of the LSAMP gene, which results in elevated anxiety and a negative effect.

Several limitations of our study should be recognized. The sample sizes were rather small, especially the PD male group. The patients in both MDD and PD groups had comorbid diagnoses. Not all associations survived correction for multiple testing, and we cannot exclude false-positive results. Also, our study lacks functional analysis of the associated SNPs. Therefore, replication association studies in independent samples and imaging genetic studies are needed to confirm and extend our findings. Further functional research is required to determine the relevance of LSAMP function to the molecular mechanisms of psychiatric disorders.

\section{Conflict of Interest}

The authors declare no conflict of interest.

Acknowledgements. We thank the patients and volunteers for the participation. This study was supported by grants from the Ministry of Science and Education (SF0180125s08) and the European Regional Development Fund.

1. Eaton WW, Kessler RC, Wittchen HU, Magee WJ. Panic and panic disorder in the United States. Am J Psychiatry 1994; 151: 413-420.

2. Kessler RC, Berglund P, Demler O, Jin R, Merikangas KR, Walters EE. Lifetime prevalence and age-of-onset distributions of DSM-IV disorders in the National Comorbidity Survey Replication. Arch Gen Psychiatry 2005; 62: 593-602.

3. Sullivan PF, Neale MC, Kendler KS. Genetic epidemiology of major depression: review and meta-analysis. Am J Psychiatry 2000; 157: 1552-1562.

4. Lesch KP. Gene-environment interaction and the genetics of depression. J Psychiatry Neurosci 2004; 29: 174-184.

5. Hettema JM, Neale MC, Kendler KS. A review and meta-analysis of the genetic epidemiology of anxiety disorders. Am J Psychiatry 2001; 158: 1568-1578.

6. Mosing MA, Gordon SD, Medland SE, Statham DJ, Nelson EC, Heath AC et al. Genetic and environmental influences on the co-morbidity between depression, panic disorder agoraphobia, and social phobia: a Twin Study. Depress Anxiety 2009; 26: 1004-1011.

7. Horton $\mathrm{HL}$, Levitt $P$. A unique membrane protein is expressed on early developing limbic system axons and cortical targets. J Neurosci 1988; 8: 4653-4661.

8. Levitt P. A monoclonal antibody to limbic system neurons. Science 1984; 223: 299-301.

9. Pimenta AF, Zhukareva V, Barbe MF, Reinoso BS, Grimley C, Henzel W et al. The limbic system-associated membrane protein is an Ig superfamily member that mediates selective neuronal growth and axon targeting. Neuron 1995; 15: 287-297.

10. Pimenta AF, Fischer I, Levitt $P$. cDNA cloning and structural analysis of the human limbicsystem-associated membrane protein (LAMP). Gene 1996; 170: 189-195.

11. Must A, Tasa G, Lang A, Vasar E, Koks S, Maron E et al. Association of limbic systemassociated membrane protein (LSAMP) to male completed suicide. BMC Med Genet 2008 9: 34 .

12. Behan AT, Byrne C, Dunn MJ, Cagney G, Cotter DR. Proteomic analysis of membrane microdomain-associated proteins in the dorsolateral prefrontal cortex in schizophrenia and bipolar disorder reveals alterations in LAMP, STXBP1 and BASP1 protein expression. $\mathrm{Mol}$ Psychiatry 2009; 14: 601-613.

13. Camp NJ, Lowry MR, Richards RL, Plenk AM, Carter C, Hensel CH et al. Genome-wide linkage analyses of extended Utah pedigrees identifies loci that influence recurrent, earlyonset major depression and anxiety disorders. Am J Med Genet B Neuropsychiatr Genet 2005; 135B: 85-93.

14. Gelernter J, Bonvicini K, Page G, Woods SW, Goddard AW, Kruger S et al. Linkage genome scan for loci predisposing to panic disorder or agoraphobia. Am J Med Genet 2001; 105: 548-557.

15. Hong KS, Won HH, Cho EY, Jeun HO, Cho SS, Lee YS et al. Genome-widely significant evidence of linkage of schizophrenia to chromosomes 2p24.3 and 6q27 in an SNP-Based analysis of Korean families. Am J Med Genet B Neuropsychiatr Genet 2009; 150B: 647-652.

16. Kaneko N, Muratake T, Kuwabara H, Kurosaki T, Takei M, Ohtsuki T et al. Autosomal linkage analysis of a Japanese single multiplex schizophrenia pedigree reveals two candidate loci on chromosomes $4 \mathrm{q}$ and 3q. Am J Med Genet B Neuropsychiatr Genet 2007; 144B: 735-742.

17. Devlin B, Bacanu SA, Roeder K, Reimherr F, Wender P, Galke B et al. Genome-wide multipoint linkage analyses of multiplex schizophrenia pedigrees from the oceanic nation of Palau. Mol Psychiatry 2002; 7: 689-694.

18. Ng MY, Levinson DF, Faraone SV, Suarez BK, DeLisi LE, Arinami T et al. Meta-analysis of 32 genome-wide linkage studies of schizophrenia. Mol Psychiatry 2009; 14: 774-785.

19. Badenhop RF, Moses MJ, Scimone A, Mitchell PB, Ewen-White KR, Rosso A et al. A genome screen of 13 bipolar affective disorder pedigrees provides evidence for susceptibility loci on chromosome 3 as well as chromosomes 9, 13 and 19. Mol Psychiatry 2002; 7: 851-859.

20. Bailer U, Leisch F, Meszaros K, Lenzinger E, Willinger U, Strobl R et al. Genome scan for susceptibility loci for schizophrenia and bipolar disorder. Biol Psychiatry 2002; 52: 40-52.

21. Auranen M, Vanhala R, Varilo T, Ayers K, Kempas E, Ylisaukko-Oja T et al. A genomewide screen for autism-spectrum disorders: evidence for a major susceptibility locus on chromosome 3q25-27. Am J Hum Genet 2002; 71: 777-790.

22. Shyn SI, Shi J, Kraft JB, Potash JB, Knowles JA, Weissman MM et al. Novel loci for major depression identified by genome-wide association study of Sequenced Treatment Alternatives to Relieve Depression and meta-analysis of three studies. Mol Psychiatry 2011; 16: 202-215.

23. Muglia P, Tozzi F, Galwey NW, Francks C, Upmanyu R, Kong XQ et al. Genome-wide association study of recurrent major depressive disorder in two European case-control cohorts. Mol Psychiatry 2010; 15: 589-601.

24. Lewis CM, Ng MY, Butler AW, Cohen-Woods S, Uher R, Pirlo K et al. Genome-wide association study of major recurrent depression in the U.K. population. Am J Psychiatry 2010; 167: 949-957.

25. Wray NR, Pergadia ML, Blackwood DH, Penninx BW, Gordon SD, Nyholt DR et al. Genome-wide association study of major depressive disorder: new results, meta-analysis, and lessons learned. Mol Psychiatry 2012; 17: 36-48.

26. Liu Y, Blackwood DH, Caesar S, de Geus EJC, Farmer A, Ferreira MAR et al. Metaanalysis of genome-wide association data of bipolar disorder and major depressive disorder. Mol Psychiatry 2011; 16: 2-4

27. Aragam N, Wang KS, Pan Y. Genome-wide association analysis of gender differences in major depressive disorder in the Netherlands NESDA and NTR population-based samples. $J$ Affect Disord 2011; 133: 516-521.

28. Terracciano A, Tanaka T, Sutin AR, Sanna S, Deiana B, Lai S et al. Genome-wide association scan of trait depression. Biol Psychiatry 2010; 68: 811-817.

29. Garriock HA, Kraft JB, Shyn SI, Peters EJ, Yokoyama JS, Jenkins GD et al. A genomewide association study of citalopram response in major depressive disorder. Biol Psychiatry 2010; 67: 133-138.

30. Nelovkov A, Philips MA, Koks S, Vasar E. Rats with low exploratory activity in the elevated plus-maze have the increased expression of limbic system-associated membrane protein gene in the periaqueductal grey. Neurosci Lett 2003; 352: 179-182.

31. Nelovkov A, Areda T, Innos J, Koks S, Vasar E. Rats displaying distinct exploratory activity also have different expression patterns of gamma-aminobutyric acid- and cholecystokininrelated genes in brain regions. Brain Res 2006; 1100: 21-31.

32. Alttoa A, Koiv K, Hinsley TA, Brass A, Harro J. Differential gene expression in a rat model of depression based on persistent differences in exploratory activity. Eur Neuropsychopharmacol 2010; 20: 288-300.

33. Innos J, Philips MA, Leidmaa E, Heinla I, Raud S, Reemann P et al. Lower anxiety and a decrease in agonistic behaviour in Lsamp-deficient mice. Behav Brain Res 2011; 217: 21-31.

34. Sheehan DV, Lecrubier Y, Sheehan KH, Amorim P, Janavs J, Weiller E et al. The MiniInternational Neuropsychiatric Interview (M.I.N.I.): the development and validation of a structured diagnostic psychiatric interview for DSM-IV and ICD-10. J Clin Psychiatry 1998; 59: 22-33

35. De la Vega FM, Lazaruk KD, Rhodes MD, Wenz MH. Assessment of two flexible and compatible SNP genotyping platforms: TaqMan SNP Genotyping Assays and the SNPlex Genotyping System. Mutat Res 2005; 573: 111-135.

36. Barrett JC, Fry B, Maller J, Daly MJ. Haploview: analysis and visualization of LD and haplotype maps. Bioinformatics 2005; 21: 263-265.

37. Pimenta AF, Levitt $P$. Characterization of the genomic structure of the mouse limbic system-associated membrane protein (Lsamp) gene. Genomics 2004; 83: 790-801.

38. Catania EH, Pimenta A, Levitt P. Genetic deletion of Lsamp causes exaggerated behavioral activation in novel environments. Behav Brain Res 2008; 188: 380-390.

39. Qiu S, Champagne DL, Peters M, Catania EH, Weeber EJ, Levitt P et al. Loss of limbic system-associated membrane protein leads to reduced hippocampal mineralocorticoid receptor expression, impaired synaptic plasticity, and spatial memory deficit. Biol Psychiatry 2010; 68: 197-204.

40. Innos J, Philips MA, Raud S, Lillevali K, Koks S, Vasar E. Deletion of the Lsamp gene lowers sensitivity to stressful environmental manipulations in mice. Behav Brain Res 2012; 228: 74-81.

(c)

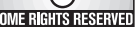
licensed under the Creative Commons Attribution-NonCommercial-No Derivative Works 3.0 Unported License. To view a copy of this license, visit http://creativecommons.org/licenses/by-nc-nd/3.0/
Translational Psychiatry is an open-access journal published by Nature Publishing Group. This work is 